\title{
ANALISIS FITUR SIRKULASI PADA INTEGRATED LIBRARY SYSTEM DI DINAS PERPUSTAKAAN DAN KEARSIPAN KABUPATEN LOMBOK TENGAH
}

\author{
Analysis of Circulation Features In Integrated Library System In The Library and \\ Archives of Central Lombok Regency
}

\author{
Fania Sita Rani ${ }^{[1]}$, Andy Hidayat Jatmika ${ }^{[2]}$, Lalu Rinjani[ ${ }^{[3]}$ \\ ${ }^{[1]}$ Dept Informatics Engineering, Mataram University \\ Jl. Majapahit 62, Mataram, Lombok NTB, INDONESIA \\ Email: titadilaga@gmail.com ${ }^{[1]}$, andy@unram.ac.id ${ }^{[2]}$, -
}

\begin{abstract}
Abstrak
Keberadaan Teknologi Informasi menjadikan sebuah perpustakaan umum dapat meningkatkan efisiensi dan efektivitasnya dalam setiap kegiatan. Hal ini dapat mengurangi pelaksanaan kerja yang bersifat manual dan menggantinya dengan sistem automasi perpustakaan yang menyediakan fasilitas untuk melakukan pelayanan. Salah satu perpustakaan umum yang baru baru ini menggunakan sistem automasi adalah Perpustakaan Umum Kabupaten Lombok Tengah. Namun, karena automasi masih baru dalam penerapannya sehingga tidak luput dari kekurangan. Salah satunya ialah beberapa fitur yang terdapat di dalam sistem masih terdapat redundansi. Praktik kerja lapangan ini bertujuan untuk menganalisis sistem yang sudah ada dan memberikan rekomendasi perbaikan agar lebih baik ke depannya.
\end{abstract}

Keywords: Analisis Fitur Sirkulasi, Rekomendasi Perbaikan Fitur, Integrated Library System.

\section{Pendahuluan}

Dengan keberadaan Teknologi Informasi, sebuah perpustakaan umum akan dapat meningkatkan efisiensi dan efektivitasnya dalam setiap kegiatan. Yang mana dengan teknologi kegiatan pengolahan perpustakaan dapat dilakukan secara otomatis. Selain itu juga dapat menjadi alat bantu bagi pustakawan dalam memberikan layanan yang cepat dan tepat bagi pengguna perpustakaan dalam mendapatkan informasi. Tentunya hal ini dapat dilakukan dengan cara mengurangai pelaksanaan kerja yang bersifat manual dan menggantinya dengan sistem automasi perpustakaan yang menyediakan fasilitas untuk melakukan sirkulasi, pembuatan label, barcode, statistik, kartu anggota, katalog yang sesuai dengan Perpustakaan Nasional Indonesia[1].

Salah satu perpustakaan umum yang baru baru ini telah menggunakan sistem automasi untuk pelayanan perpustakaan adalah Perpustakaan Umum Kabupaten Lombok Tengah. Perpustakaan ini melakukan automasi terhitung sudah berjalan kurang lebih satu tahun. Untuk mencapai pelayanan perpustakaan yang baik diperlukan tenaga profesional yang baik kemudian didukung oleh alat dan sistem yang mumpuni. Dalam penerapannya, perpustakaan ini telah berjalan cukup efektif. Namun, karena automasi pada Dinas Perpustakaan dan Kearsipan Kabupaten Lombok Tengah masih baru dalam penerapannya sehingga tidak luput dari kekurangan. Salah satunya ialah beberapa fitur yang terdapat di dalam sistem masih terdapat redundansi. Redundansi merupakan kejadian berulangnya data atau kumpulan data yang sama dalam sebuah database yang mengakibatkan pemborosan media penyimpanan.

Sejalan dengan latar belakang tersebut penulis menggagas judul Praktik Kerja Lapangan yakni "Analisis Fitur Sirkulasi Pada Integrated Library System di Dinas Perpustakaan dan Kearsipan Kabupaten Lombok Tengah”.

\section{TinjaUAN PUSTAKa}

\subsection{Analisis Sistem}

Analisis sistem merupakan tahapan paling awal dari pengembangan sistem yang menjadi fondasi menentukan keberhasilan sistem informasi yang dihasilkan nantinya. Analis sistem adalah sebuah istilah yang secara kolektif mendeskripsikan fase-fase awal pengembangan awal. Analisa sistem adalah penguraian dari suatu sistem informasi yang utuh ke dalam bagian-bagian komponennya dengan maksud untuk mengidentifikasikan dan mengevaluasi permasalahan-permasalahan yang diharapkan sehingga dapat di usulkan perbaikan-perbaikannya. 
Analisis sistem secara sistematis menilai bagaimana fungsi dengan cara mengamati proses input dan data proses output informasi untuk membantu peningkatan proses organisasional[2].

\subsection{Sistem Automasi Perpustakaan}

Sistem automasi perpustakaan dikatakan baik apa bila layanan-layanannya sudah terintegrasi antara satu dengan yang lain, mulai dari sistem pengadaan bahan Pustaka, pengolahan bahan pustaka, sistem pencarian kembali bahan pustaka, sistem sirkulasi, membership, pengaturan denda keterlambatan pengembalian, dan sistem pelaporan aktivitas perpustakaan dengan berbagai parameter pilihan[3].

Menurut Cochrane dalam Mahmun, tujuan automasi perpustakaan adalah:

a. Memudahkan integrasi kegiatan perpustakaan.

b. Memudahkan kerja sama dan pembentukan jaringan perpustakaan.

c. Membantu menghindari duplikasi kegiatan di perpustakaan.

d. Menghindari dari pekerjaan yang bersifat mengulang dan membosankan.

e. Memberikan peluang untuk memasarkan jasa perpustakaan.

f. Meningkatkan efisiensi.

\subsection{Sistem Informasi}

Sistem Informasi merupakan suatu sistem di dalam organisasi yang mempertemukan kebutuhan pengolahan transaksi harian yang mendukung fungsi operasi organisasi yang bersifat manajerial[4].

\subsection{Basis Data}

Basis data terdiri dari 2 kata, yaitu Basis dan Data. Basis kurang lebih diartikan sebagai markas atau gudang, tempat bersarang/berkumpul. Sedangkan Data adalah representasi fakta dunia nyata yang mewakili suatu objek seperti manusia (pegawai, siswa, pembeli, pelanggan), barang, hewan, peristiwa, konsep, keadaan, dan sebagainya, yang direkam dalam bentuk angka, huruf, simbol, teks, gambar, bunyi/suara, atau kombinasinya[5].

\subsection{Framework Codeigniter}

Codelgniter merupakan sebuah framework yang dibuat dengan menggunakan bahasa PHP, yang dapat digunakan untuk pengembangan web secara cepat. Adapun framework sendiri dapat diartikan sebagai suatu struktur pustaka-pustaka, kelas-kelas dan infrastruktur run-time yang dapat digunakan oleh programmer untuk mengembangkan aplikasi web secara cepat. Tujuan penggunaan framework adalah untuk mempermudah pengembang web mengembangkan aplikasi web yang robust secara cepat tanpa kehilangan fleksibilitas[6].

\subsection{MySQL}

MySQL (My Structured Query Language) adalah: " Suatu sistem basis data relation atau Relational Database Management System (RDBMS) yang mampu bekerja secara cepat dan mudah digunakan MySQL juga merupakan program pengakses database yang bersifat jaringan, sehingga sapat digunakan untuk aplikasi multi user (banyak pengguna). MySQL didistribusikan gratis di bawah lisensi GPL (General Public License). Dimana setiap program bebas menggunakan MySQL namun tidak bisa dijadikan produk turunan yang dijadikan closed source atau komersial"[7].

\subsection{XАMPP}

Menurut MADCOMS (2016) "Xampp adalah sebuah paket kumpulan software yang terdiri dari Apache, MySQL, PhpMyAdmin, PHP, Perl, Filezilla, dan lain-lain.” Xampp berfungsi untuk memudahkan instalasi lingkungan PHP, di mana biasanya lingkungan pengembangan web memerlukan PHP, Apache, MySQL dan PhpMyAdmin[8].

\section{Metode}

\subsection{Perancangan Desain}

Tahap perancangan desain dari Fitur Sirkulasi Integrated Library System terdiri dari flow chart, use case diagram, entity relationship diagram, dan desain usser interface. Pada tahap ini dilakukan penggambaran, perencanaan dan pembuatan sketsa atau pengaturan dari beberapa elemen yang terpisah ke dalam satu kesatuan yang utuh dan berfungsi.

\subsection{Flow Chart}


Rancangan fitur yang ditawarkan penulis pada sistem yang sudah ada sebelumnya, sudah tidak ada subfitur yang mengalami redundansi dalam implementasinya. Sub-fitur entri peminjaman susulan sudah disatukan dengan sub-fitur entri peminjaman. Sub-fitur entri pengembalian susulan, sub-fitur entri pengembalian gabungan untuk tugas dan fungsi utamanya, telah disatukan dengan sub-fitur entri pengembalian seperti pada Gambar 1.

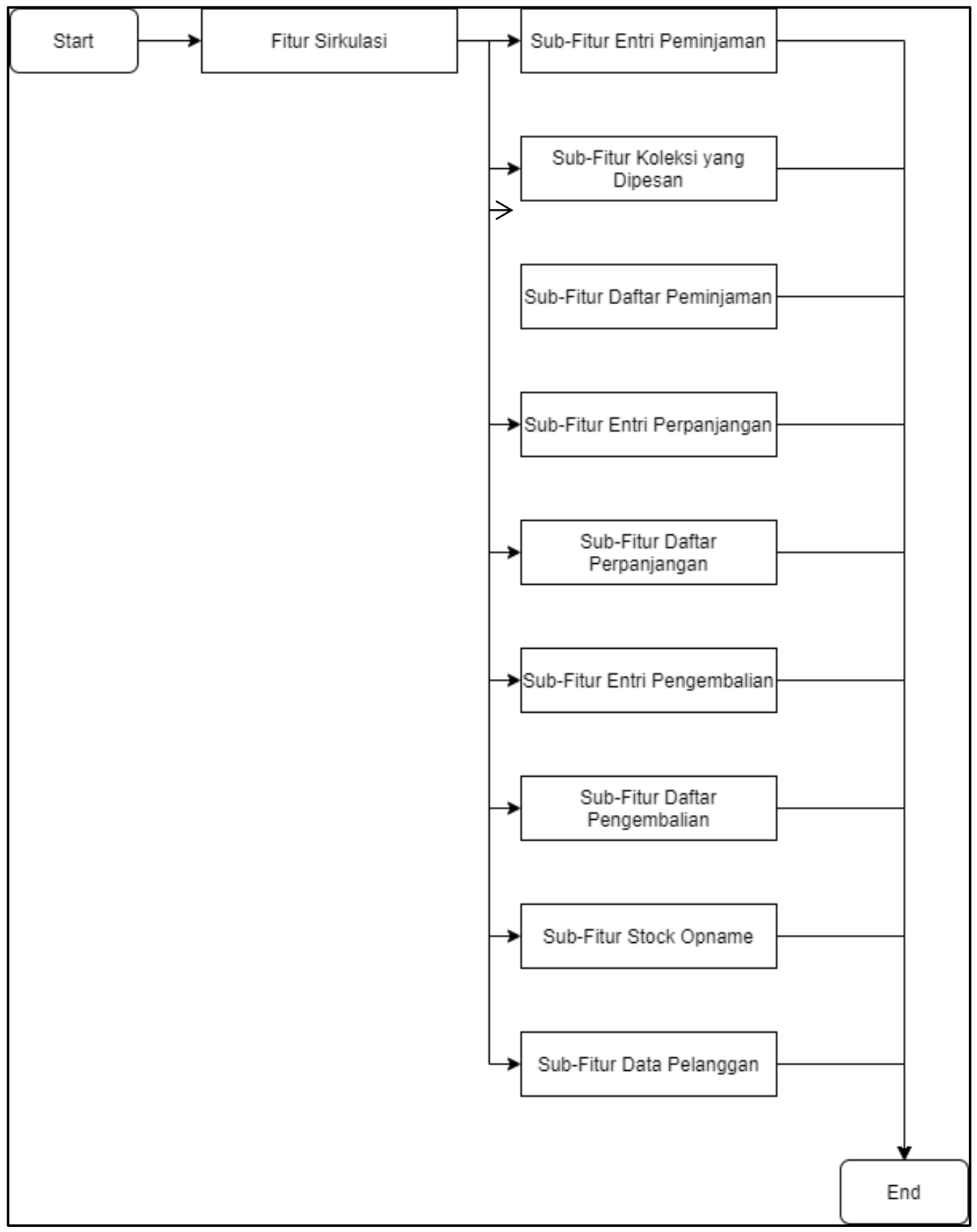

Gambar 1. Flow Chart Fitur Sirkulasi 


\subsection{Use Case Diagram}

Use Case diagram pada Gambar 2 bertujuan untuk menjelaskan apa saja yang dapat dilakukan admin di dalam sistem. Terdapat satu orang user pada sistem ini.

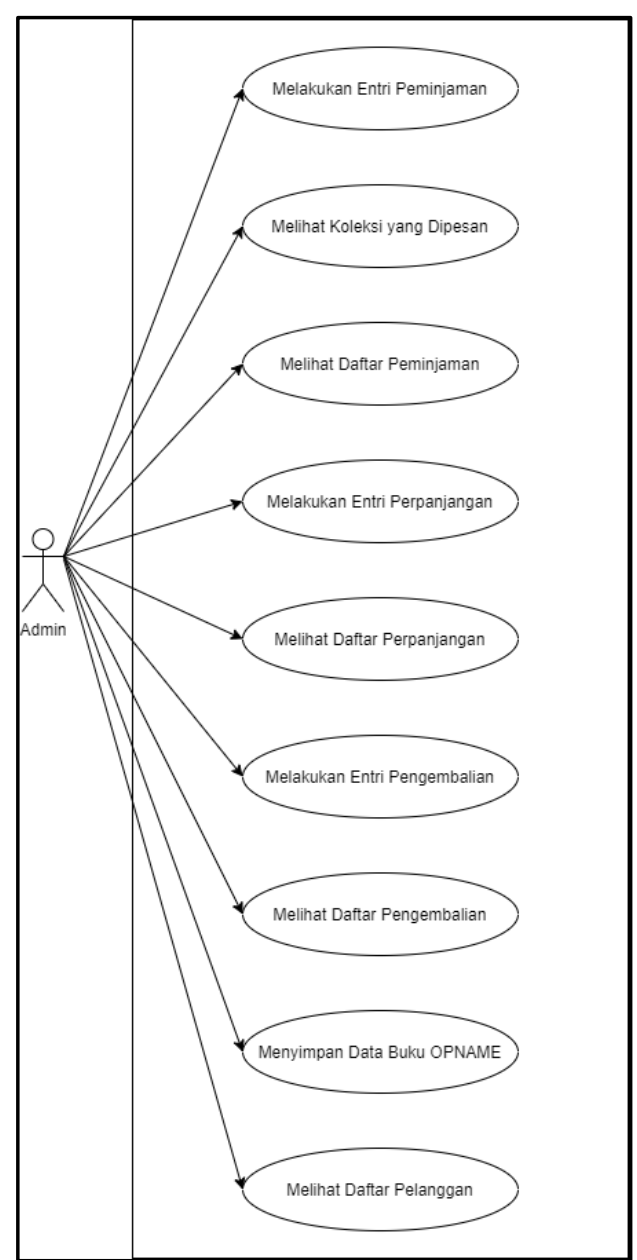

Gambar 2. Use Case Diagram Fitur Sirkulasi

Use case diagram pada Gambar 2 merupakan gambaran aktivitas yang dapat dilakukan oleh admin pada fitur sirkulasi di Integrated Library System, yakni :

a. Entri Peminjaman

Entri Peminjaman adalah form yang harus diisi oleh admin yang diisikan ID dari pelanggan dan ID buku agar buku dapat dipinjam.

b. Melihat Koleksi yang Dipesan

Daftar koleksi yang dipesan adalah daftar koleksi yang dipesan anggota melalui OPAC.

c. Melihat Daftar Peminjaman

Daftar Peminjaman untuk melihat daftar anggota yang meminjam item koleksi apa saja. Akan ditampilkan daftar anggota serta item koleksi yang dipinjam.

d. Melakukan Entri Perpanjangan

Entri Perpanjangan merupakan form isian berupa tanggal apabila anggota ingin melakukan perpanjangan masa pinjam.

e. Melihat Daftar Perpanjangan

Daftar Perpanjangan untuk melihat daftar anggota yang memperpanjang peminjaman item koleksi apa saja. Akan ditampilkan daftar anggota serta item koleksi yang diperpanjang.

f. Melakukan Entri Pengembalian

Entri Pengembalian adalah ketika anggota mengembalikan item yang dipinjam, data pengembaliannya berupa peng-input-an ID buku.

g. Melihat Daftar Pengembalian 
Daftar Pengembalian untuk melihat daftar anggota yang mengembalikan item koleksi apa saja. Akan ditampilkan daftar anggota serta item koleksi yang dikembalikan.

h. Menyimpan Data Buku Opname

Stock Opname digunakan untuk penyimpanan data-data buku yang masuk dalam stock Opname.

i. Melihat Daftar Pelanggaran

Daftar pelanggan digunakan untuk melihat siapa saja anggota yang melakukan pelanggaran.

\subsection{Entity Relationship Diagram}

Salah satu komponen utama dalam sistem informasi adalah terdapat suatu basis data. Pada Gambar 3 digambarkan Entity Relationship Diagram Fitur Sirkulasi.

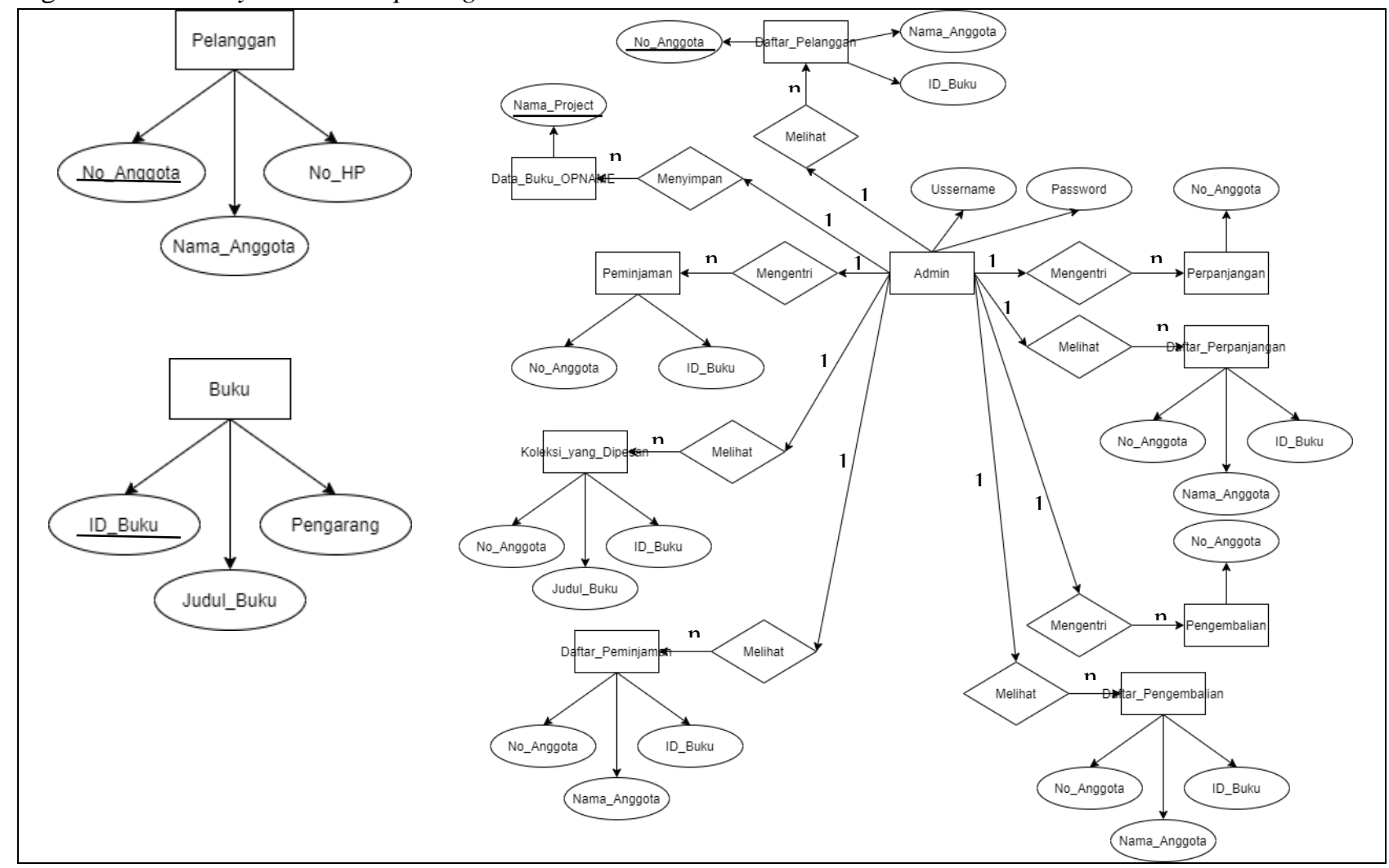

Gambar 3. Entity Relationship Diagram

Pada Gambar 3, Entity Relationsip Diagram (ERD) untuk rancangan Fitur Sirkulasi untuk Integrated Library System terdapat sebelas entitas. Entitas pertama terdapat Admin dengan atribut username dan password. Entitas kedua, Peminjaman yang memiliki atribut No_Anggota dan ID_Buku. Ketiga, entitas Daftar_Peminjaman dengan atribut No_Anggota, ID_Buku, dan Nama_Anggota. Kemudian keempat terdapat entitas Koleksi_yang_Dipesan dengan atribut No_Anggota, ID_Buku, dan Judul_Buku. Terdapat entitas Data_Buku_Opname dengan atribut Nama_Project. Entitas Perpanjangan yang memiliki atribut No_Anggota. Kemudian ada entitas Daftar_Perpanjangan dengan atribut No_Anggota dan ID_Buku. Selanjutnya terdapat entitas Pengembalian dengan atribut No_Anggota. Terdapat entitas Daftar_Pengembalian dengan atribut No_Anggota, Nama_Anggota, dan ID_Buku . Entitas Daftar_Pelanggaran memiliki atribut No_Anggota, ID_Buku, dan Nama_Anggota. Dimana beberapa entitas ini berelasi langsung dengan entitas admin. Terdapat entitas buku yang memiliki atribut ID_Buku, Judul_Buku, dan Pengarang. Terakhir terdapat entitas Pelanggan dengan atribut No_Anggota, Nama_Anggota, dan No_HP. 


\subsection{Implementasi Sistem}

\section{HASil Dan PeMbahasan}

Implementasi pembuatan sistem informasi De La Sirra Café \& Resto menggunakan PHP MySQL sebagai backend dan CodeIgniter sebagai framework dalam implementasinya. Implementasi pembuatan fitur pada sistem terdapat tampilan halaman yang dimiliki antara lain :

a. Entri Peminjaman

Merupakan implementasi dari rancangan halaman Entri Peminjaman yang akan muncul ketika admin mengakses halaman Entri Peminjaman.

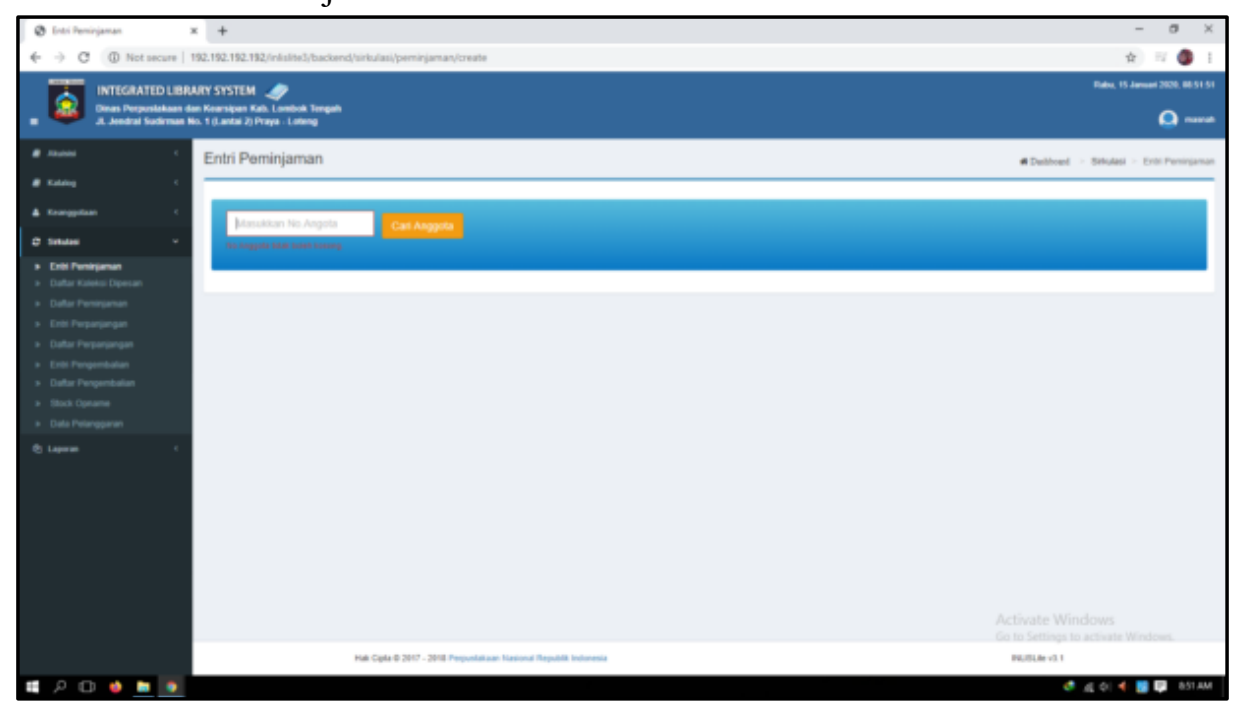

Gambar 4. Entri Peminjaman

b. Koleksi yang Dipesan

Implementasi dari rancangan halaman Koleksi yang Dipesan yang akan muncul ketika admin mengakses halaman Koleksi yang Dipesan.

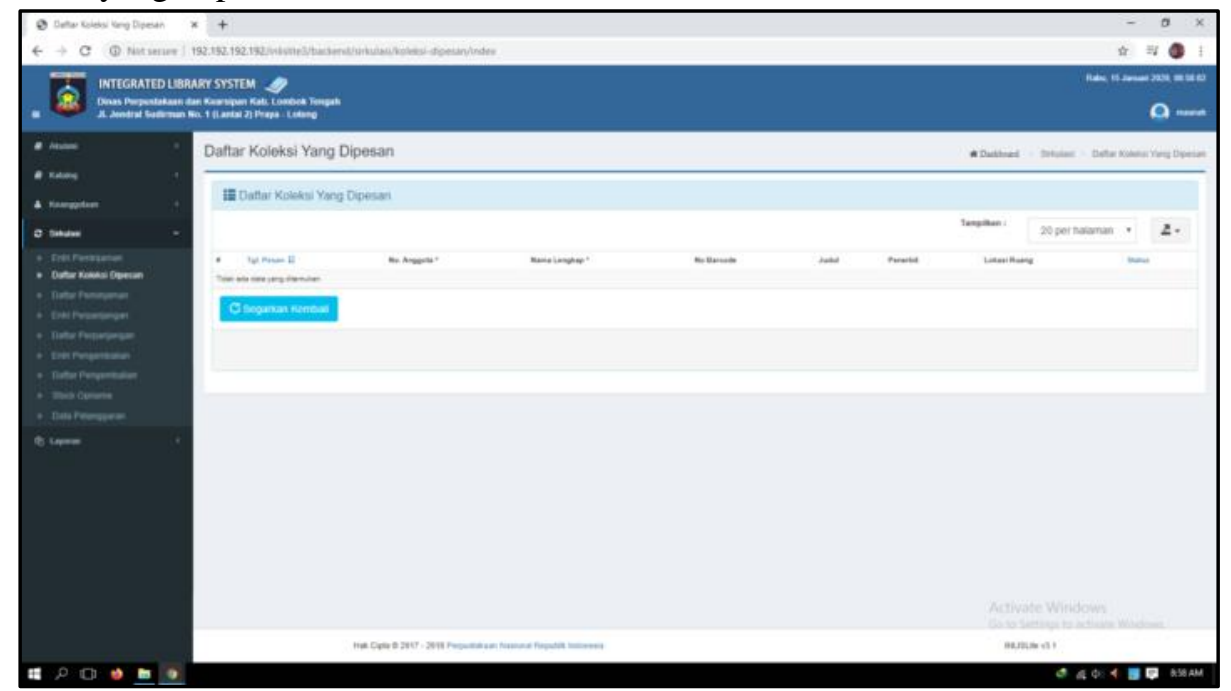

Gambar 5. Koleksi yang Dipesan 
c. Daftar Peminjaman

Implementasi dari rancangan halaman Daftar Peminjaman yang akan muncul ketika admin mengakses halaman Daftar Peminjaman.

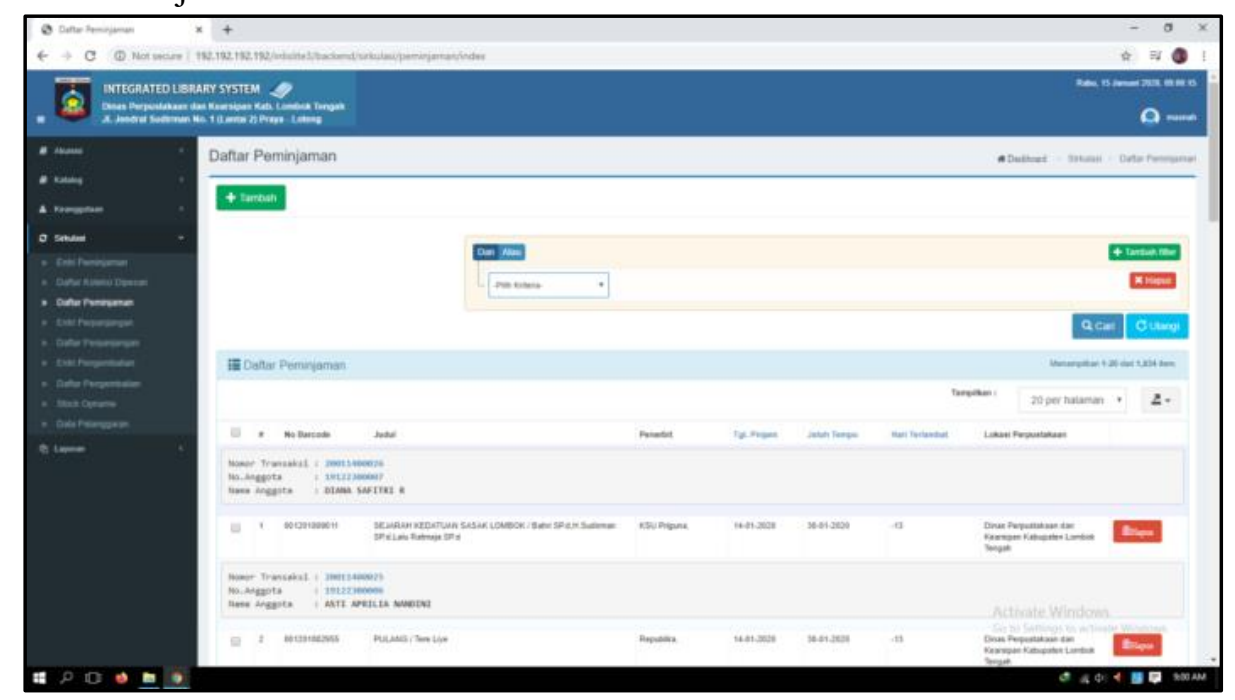

Gambar 6. Daftar Peminjaman

d. Entri Perpanjangan

Implementasi dari rancangan halaman Entri Perpanjangan yang akan muncul ketika admin mengakses halaman EntriPerpanjangan.

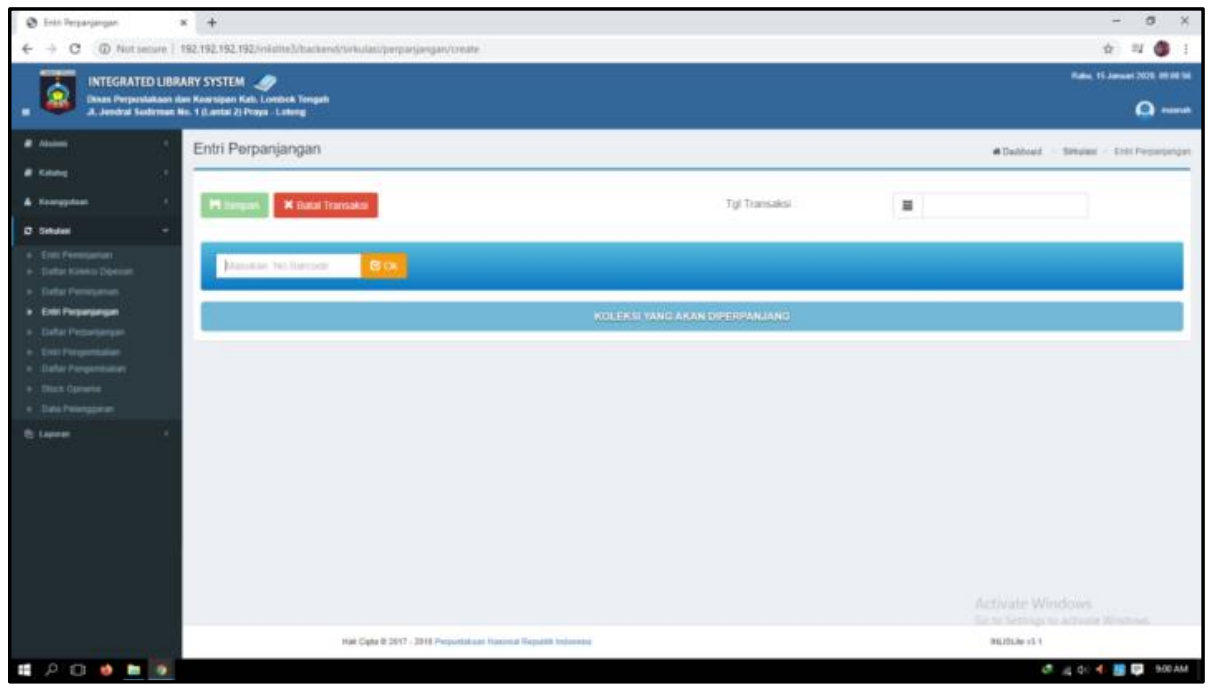

Gambar 7. Entri Perpanjangan 
e. Daftar Perpanjangan

Implementasi dari rancangan halaman Daftar Perpanjangan yang akan muncul ketika admin mengakses halaman Daftar Perpanjangan.

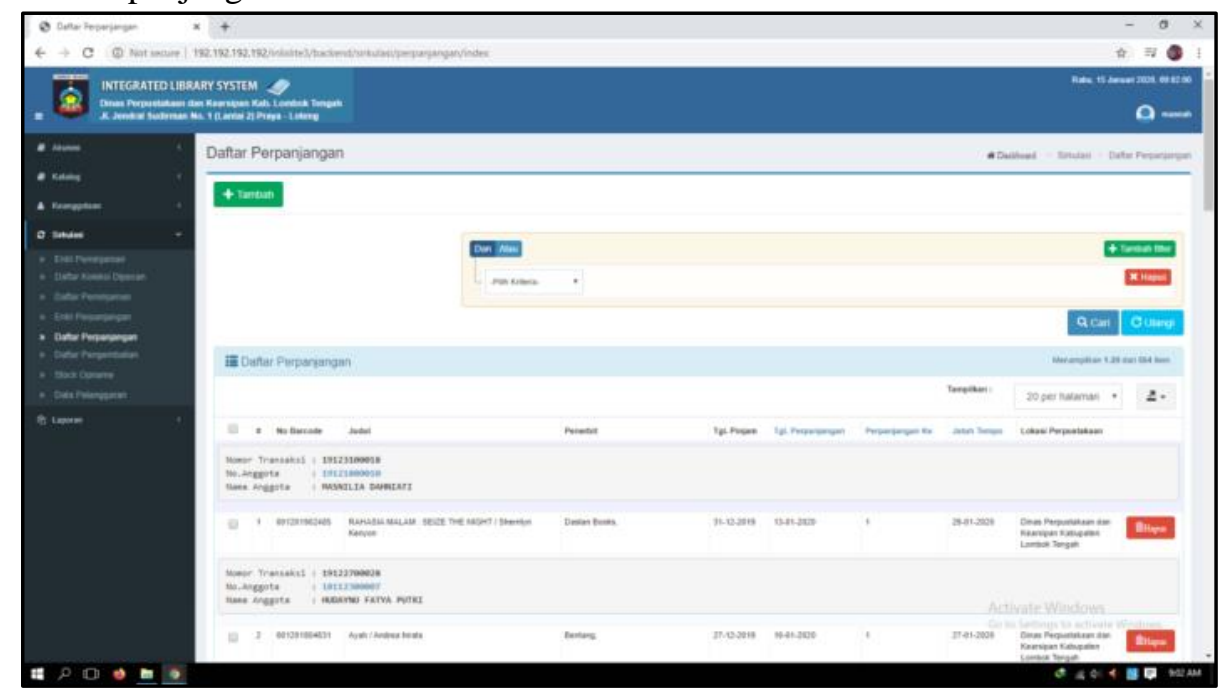

Gambar 8. Daftar Perpanjangan

f. Entri Pengembalian

Implementasi dari rancangan halaman Entri Pengembalian yang akan muncul ketika admin mengakses halaman Entri Pengembalian.

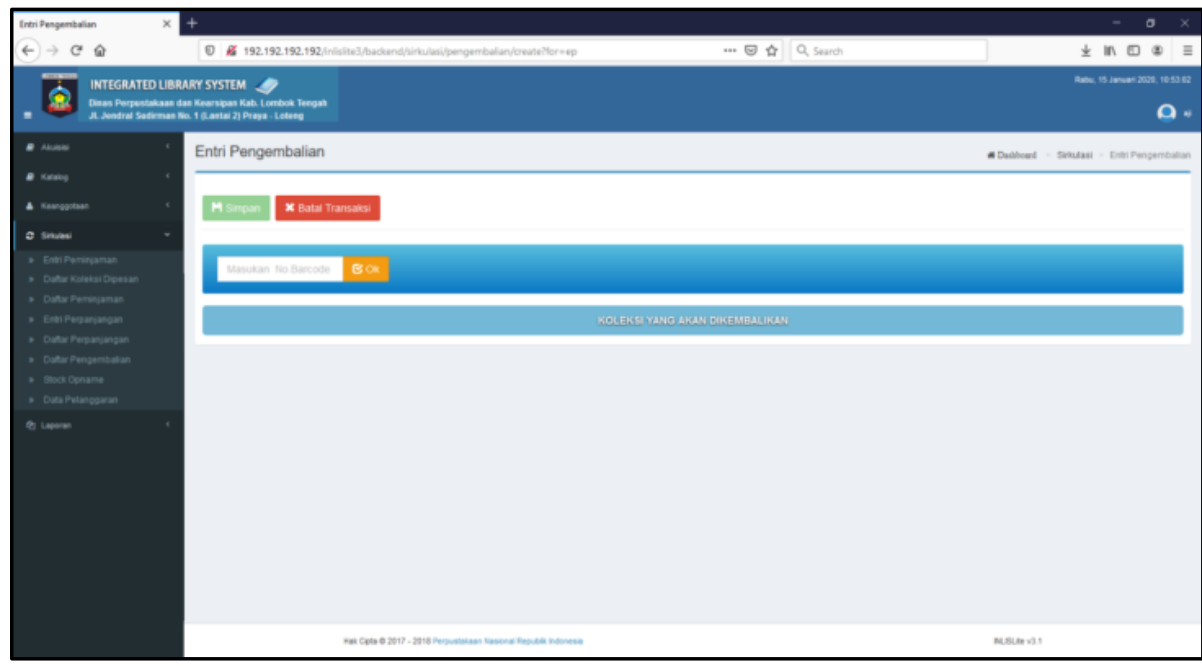

Gambar 9. Entri Pengembalian 
g. Daftar Pengembalian

Implementasi dari rancangan halaman Daftar Pengembalian yang akan muncul ketika admin mengakses halaman Daftar Pengembalian.

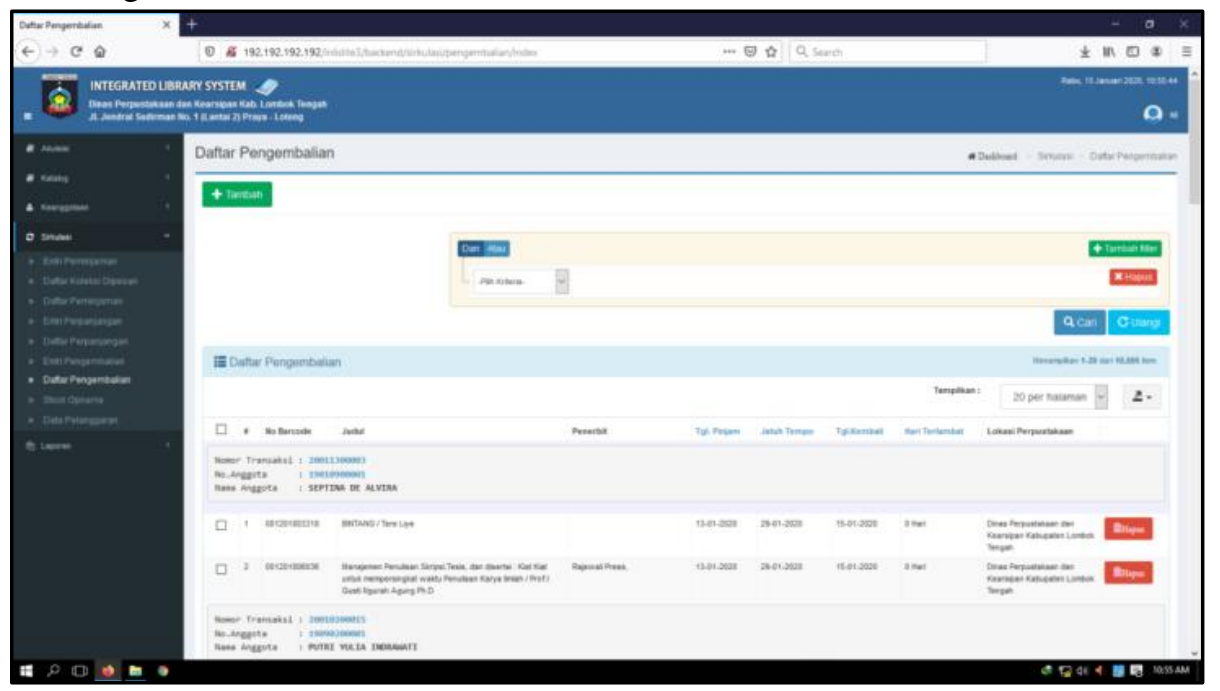

Gambar 10. Daftar Pengembalian

h. Stock Opname

Implementasi dari rancangan halaman Stock Opname yang akan muncul ketika admin mengakses halaman Stock Opname.

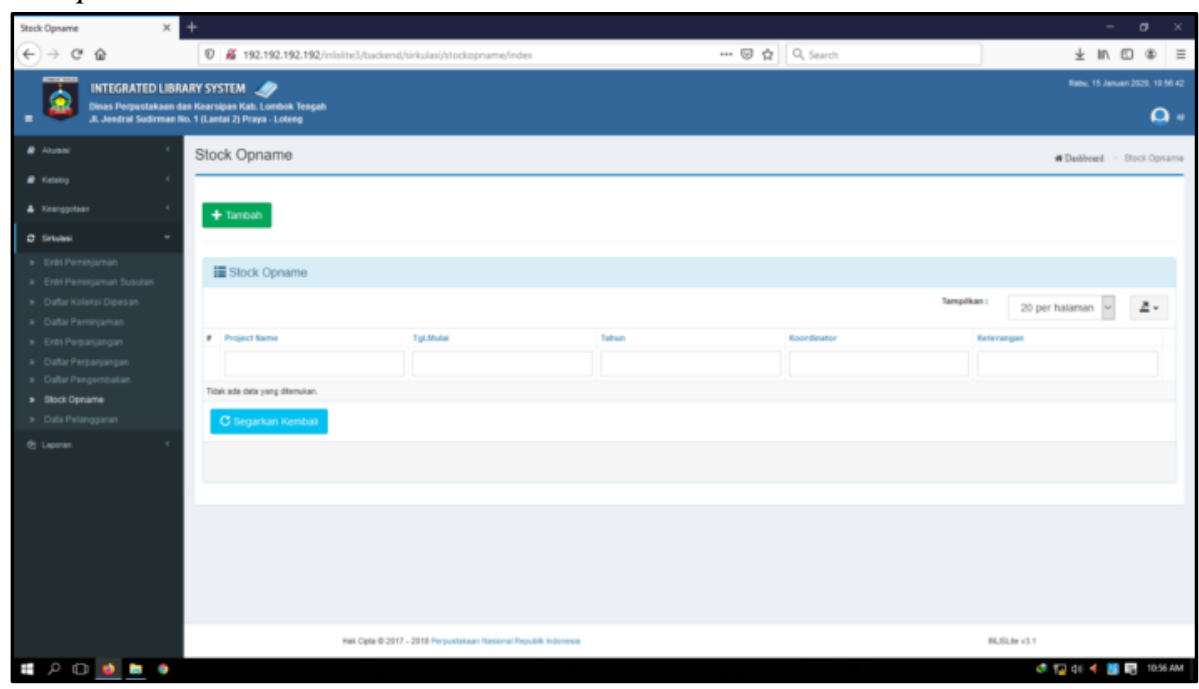

Gambar 11. Stock Opname 
i. Daftar Pelanggaran

Implementasi dari rancangan halaman Daftar Pelanggaran yang akan muncul ketika admin mengakses halaman Daftar Pelanggaran

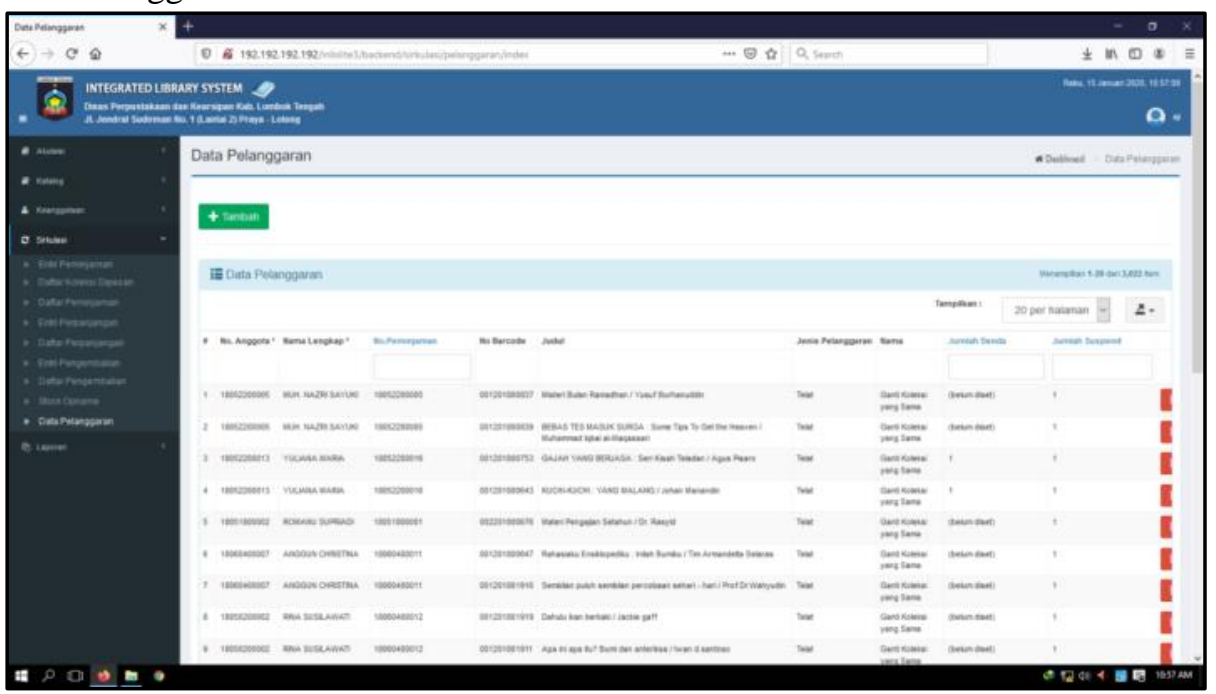

Gambar 12. Daftar Pelanggaran

\subsection{Pembahasan Sistem}

Pengembangan Fitur Sirkulasi melalui beberapa tahapan yakni menganalisis permasalahan yang dialami oleh Dinas Perpustakaan dan Kearsipan Kabupaten Lombok Tengah khususnya pada bagian pelayanan. Penulis mengusulkan untuk menghilangkan redundansi pada Sistem yang digunakan sebelumnya. Selanjutnya dilakukan analisis kebutuhan data dan fitur apa saja yang akan tetap digunakan dalam pembuatan rancangan ini.

Fitur terbaru mendapatkan feedback yang positif dari pihak kantor. Menurut user experience fitur terbaru sangat memudahkan dalam proses pelayanan. Ke depannya diharapkan dapat dikembangkan lebih jauh.

\subsection{Pengujian Rancangan Sistem}

TABEL 1. PENGUJIAN RANCANGAN SISTEM DENGAN KUISIONER

\begin{tabular}{|c|l|c|c|c|c|c|}
\hline \multirow{2}{*}{ No. } & \multicolumn{6}{c|}{ Pilihan Jawaban } \\
\cline { 3 - 7 } & & SS & S & C & TS & STS \\
\hline 1. & Tampilan sistem sudah baik dan mudah di gunakan & 9 & 3 & 0 & 0 & 0 \\
\hline 2. & Pekerjaan admin menjadi lebih efisien & 8 & 4 & 0 & 0 & 0 \\
\hline 3. & Menunjang kinerja instansi & 5 & 7 & 0 & 0 & 0 \\
\hline 4. & Memenuhi syarat kerja instansi & 6 & 6 & 0 & 0 & 0 \\
\hline \multicolumn{2}{c|}{ Total } & 28 & 20 & & & \\
\hline \multicolumn{2}{c|}{ Rata - Rata (\%) } & $58 \%$ & $42 \%$ & $0 \%$ & $0 \%$ & $0 \%$ \\
\hline
\end{tabular}

\section{KESIMPULAN DAN SARAN}

Berikut kesimpulan yang dapat ditarik setelah dilakukan analisa terhadap fitur sirkulasi Integrated Library System Perpustakaan Daerah Kabupaten Lombok Tengah :

1. Tampilan rancangan fitur sirkulasi sudah baik dan dapat memudahkan admin di Perpustakaan Daerah Kabupaten Lombok Tengah sesuai dengan hasil kuesioner yang telah diisi oleh 12 orang responden dengan persentase jawaban sangat setuju sebesar $90 \%$.

2. Pekerjaan admin menjadi lebih efisien dengan persentase sangat setuju sebesar $80 \%$. 
3. Sistem sudah memenuhi syarat sesuai dengan kinerja instansi dan sangat menunjang kinerja instansi dengan persentase jawaban sangat setuju sebesar 50\% dan setuju sebesar $50 \%$.

Usulan rancangan sistem ini masih belum dapat dikatakan sempurna, untuk itu terdapat saran yang diharapkan mampu menjadi perhatian untuk pengembangan sistem selanjutnya yakni :

1. Diharapkan pengembangan sistem ke depannya dapat lebih variatif dalam pengaturan user interface agar tidak terkesan monoton.

2. Dalam pengembangan sistem, alangkah lebih baiknya jika dikaji lebih mendetail agar terpenuhi kebutuhan dari pihak admin maupun anggota perpustakaan.

\section{DAFTAR PUSTAKa}

[1] Marshella, Suary dan Marlini, "Efektivitas Penerapan Sistem Automasi Perpustakaan Di Perpustakaan Umum Gunung Bungsu Kota Batusangkar", Jurnal Ilmu Informasi Perpustakaan dan Kearsipan Vol. 3, No. 1, Seri A, September 2014.

[2] Muhidin, Rusli. et al, "Analisis Dan Perancangan Sistem Informasi Pada SMA Negeri 18 Halmahera Selatan Sebagai Media Promosi Berbasis Web”, Volume 2 Nomor 2 | ISSN 2548-6438, September 2017.

[3] Hutama, Abrian Satria, dan Yuli Rohmiati, "Pengaruh Penerapan Sistem Automasi Perpustakaan Izylib Terhadap Kualitas Layanan di Perpustakaan SMA Negeri 1 Semarang", 2013.

[4] Adiguna, Arel Riedsa. et al, "Analisis dan Perancangan Sistem Informasi Manajemen Gudang pada PT Mitra Pinasthika Mulia Surabaya", Jurnal Pengembangan Teknologi Informasi dan Ilmu Komputer e-ISSN: 2548-964X Vol. 2, No. 2, hlm. 612-621, Februari 2018.

[5] Fathansyah. Basis Data. Bandung : Informatika, 2007.

[6] Afuan, Lasmedi, "Pengembangan Sistem Informasi Pendataan Laporan Kerja Praktek Mahasiswa Program Studi Teknik Informatika Unsoed”, JUITA Vol. I Nomor 2, Nopember 2010.

[7] Destiningrum, Mara dan Qadhli Jafar Adrian, "Sistem Informasi Penjadwalan Dokter Berbassis Web Dengan Menggunakan Framework Codeigniter (Studi Kasus: Rumah Sakit Yukum Medical Centre)", Jurnal TEKNOINFO, Vol. 11, No. 2, pp. 30-37. ISSN 1693 0010, 2017.

[8] Ayu, Fitri dan Nia Permatasari, "Perancangan Sistem Informasi Pengolahan Data Praktek Kerja Lapangan (PKL) Pada Devisi Humas Pt. Pegadaian”, Volume 2, No.2 ISSN. 2549-0222 Jurnal Intra-Tech, Oktober 2018. 